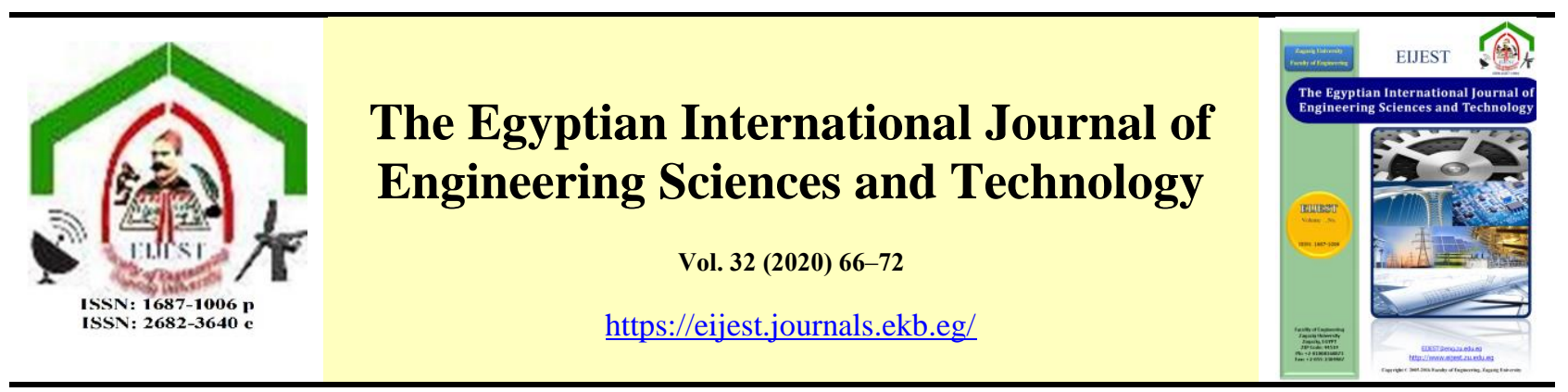

\title{
Effect of Aspect Ratio on Aerodynamic Performance of Archimedes spiral Wind Turbine
}

\begin{tabular}{|c|c|}
\hline A R T I C LE I NF O & A B S T RA C T \\
\hline $\begin{array}{l}\text { Keywords: } \\
\text { Archimedes spiral blades } \\
\text { Aspect ratio } \\
\text { Computational simulation } \\
\text { ANSYS-CFX }\end{array}$ & $\begin{array}{l}\text { This study describes the effect of aspect ratio on the aerodynamic performance of } \\
\text { small-scale Archimedes spiral-wind-turbine. The computational approach was used } \\
\text { to predict the aerodynamic performance of the scaled-down rotor blades. Aspect } \\
\text { ratio is defined by the ratio of turbine diameter to its length. The present study } \\
\text { includes five different models for three different aspect ratios } 1.5,1.25 \text { and } 1.0 \text { with } \\
\text { forward and backward elongation. The computational study was carried out using } \\
\text { the ANSYS-CFX } 19 \text { software for a steady incompressible flow. The performance } \\
\text { parameters of the wind turbine, which are power and torque coefficients, were } \\
\text { explored for different aspect ratios. This was carried out for wind speed from } 5 \text { to } \\
12 \mathrm{~m} / \mathrm{s} \text { with an interval of } 1 \mathrm{~m} / \mathrm{s} \text {. In order to save computational time, the } \\
\text { computational models were } 1 / 10 \mathrm{down} \text {-scaled of the } 0.5 \mathrm{~kW} \text { class which has } 1.5 \mathrm{~m} \text { - } \\
\text { diameter. In order to validate the results of the computational simulation, the } \\
\text { present results were compared to previous research results of others. Obviously, the } \\
\text { results highlight that the less aspect ratio with forward elongation, the more } \\
\text { resulting power coefficient. }\end{array}$ \\
\hline
\end{tabular}

\section{Introduction}

For securing energy supply, handling the climate change issues, preventing of Greenhouse Gas (GHG) emissions, and biodiversity protection, evolution of renewable technologies, energy conservation, and efficiency improvements are becoming very important. One of the most important renewable resources is the wind energy, which is a relatively mature technology with enormous prospect for commercialization and mass production. The major application of wind power is electricity generation from large grid-connected wind farms [1]. With the extending of the power grid and the reduction of electricity rare areas, small-scale wind turbines are now being utilized in several countries and in many fields, such as mobile communication base-stations, sea-water desalination, offshore aquaculture, and city road lighting [2]. Small-scale wind turbines can be classified into Horizontal-Axis Wind Turbines (HAWT) and Vertical-Axis Wind Turbines (VAWT).

Ahmed [3] investigated the advantages of smallscale wind turbines including low cost, low noise, easy and safe method for power generation by using both Computational Fluid Dynamics (CFD) and wind tunnel test methods. He studied small-scale wind turbines with less than $10 \mathrm{~kW}$ of output power by comparing the power curves. A variety of wind turbines were analyzed [4-7]. These studies stated the effect of the blade geometry on the power coefficient curve, the turbine's rated power with respect to its swept frontal area, the output electricity production, and the pay-back period.

The Archimedes spiral-wind-turbine has proven its efficiency among all types of small-scale wind 
turbines because it overcomes many restrictions of other wind turbines like noise level, and yawing system as it is automatically directed to the wind direction due to drag force [8]. The most important that it has a high efficiency at the low tip-speed ratios relative to other small-scale wind turbines like Savonius wind turbines [8]. Lu et al. [9] invented a new method to investigate the aerodynamic performance based on the angular momentum theory in addition to numerical analysis. Kim et al. [10-12] studied the flow characteristic around the 1/10 downscaled model using numerical and Particle Image Velocimetry (PIV) methods. Safdari and Kim [13] studied the aerodynamic performance for a scaleddown model. Li et al. and Ji et al. [14, 15] studied the effect of the angle of attack on Archimedes spiralwind-turbine using PIV method. Yang et al. [16] invented an industrial method for the turbine mass production. $\mathrm{Ji}$ et al. [17, 18] investigated the aerodynamic performance of the full-scale model at different wind tunnel cross-sectional areas. Chaudhary et al. [19] studied the aerodynamic forces for another model of Archimedes spiral-wind-turbine using numerical and field tests. Sandeep et al. and Rao et al. [20, 21] modified the turbine blades using NACA 2412 and NACA 6409 airfoils, respectively. Ebrahimi and Ghassemi [22] made two studies for $1 / 10$ down-scaled and full-scale of the $0.5 \mathrm{~kW}$ class. Jang et al. [23] studied the aerodynamic performance of full-scale model with different geometry using numerical and field tests.

The above literature review shows the real need for more investigation about the effect of aspect ratio on the aerodynamic performance of the Archimedes spiral-wind-turbine.

The $0.5 \mathrm{~kW}$ class of Archimedes spiral-windturbine has a diameter of $1.5 \mathrm{~m}[10,12-15,18,23$, 24]. Four independent parameters describe the geometry of the Archimedes spiral-wind-turbine, namely: the outer diameter, turbine length, inclination angle which is the angle between the tip of the blade and horizontal axis from back side, and blade angle which is the angle between tip of the blade and the horizontal axis from front side. Thus, Fig. 1 shows the schematic diagram of 1/10 downscaled model of $0.5 \mathrm{~kW}$-turbine, which is numerically investigated in the present study.

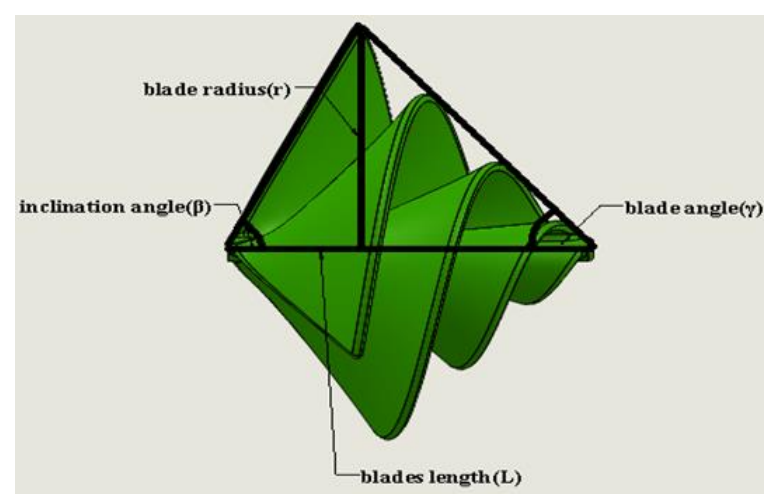

Figure 1: Geometrical parameters of Archimedes spiral-wind-turbine.

The aspect ratio (AR) is the ratio between the outer diameter and the turbine length. In this study, the outer diameter is constant for the five models. At least, one of the blades or inclination angles is automatically changed with the change of aspect ratio depending on the side of elongation. Table [1] shows the geometry parameters of $1 / 10$ down-scaled models of the present study.

Table 1: Geometry parameters of the 1/10 down-scaled models.

\begin{tabular}{|c|c|c|c|c|c|c|}
\hline $\begin{array}{c}\text { Model } \\
\text { No }\end{array}$ & $\begin{array}{c}\mathrm{D} \\
(\mathrm{cm})\end{array}$ & $\begin{array}{c}\mathrm{L} \\
(\mathrm{cm})\end{array}$ & $\begin{array}{c}\text { Elong- } \\
\text { ation } \\
\text { side }\end{array}$ & $\begin{array}{c}\mathrm{AR} \\
(\mathrm{D} / \mathrm{L})\end{array}$ & $\begin{array}{c}\gamma \\
\operatorname{deg}\end{array}$ & $\begin{array}{c}\beta \\
\operatorname{deg}\end{array}$ \\
\hline 1 & 15 & 10 & - & 1.5 & 50.00 & 63.69 \\
\hline 2 & 15 & 12 & Front & 1.25 & 42.12 & 63.69 \\
\hline 3 & 15 & 12 & Back & 1.25 & 50.00 & 52.73 \\
\hline 4 & 15 & 15 & Front & 1 & 33.58 & 63.69 \\
\hline 5 & 15 & 15 & Back & 1 & 50.00 & 40.74 \\
\hline
\end{tabular}

\section{Methodology}

Five 3D models of the Archimedes wind turbine were designed using Solidworks ver. 2018 software at the different aspect ratios (AR) as shown in figure [2].

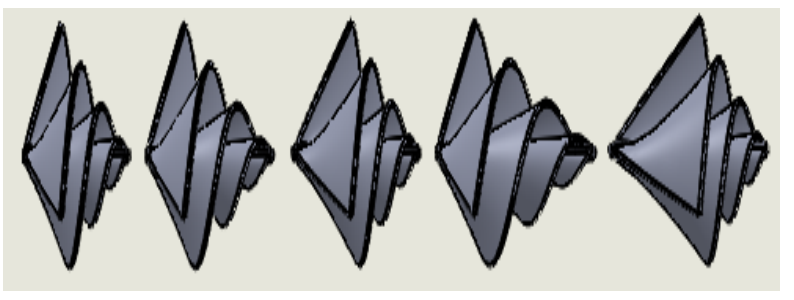

Figure 2: Present five 3D models of Archimedes windturbines. 
CFD investigation was carried out using ANSYS-CFX ver. 19.0.

In order to save computational run-time, tetrahedral elements were used in the computational mesh. [9-12, 19, 22, 23] as shown in Figure 3. At the turbine face, the smallest dimension of the mesh element was set to be $3 \mathrm{~mm}$, which was equal to the minimum thickness of the rotor blades. The first layer height of the mesh was set to $0.1 \mathrm{~mm}$ to ensure that the value of $\mathrm{Y}^{+}$next to the blade is approximately 4 as shown in Figure 4 [10, 22]. The mesh size at the interface between the stationary and rotating domains was set to $5 \mathrm{~mm}$ to give a homogeneous and continuous flow field.

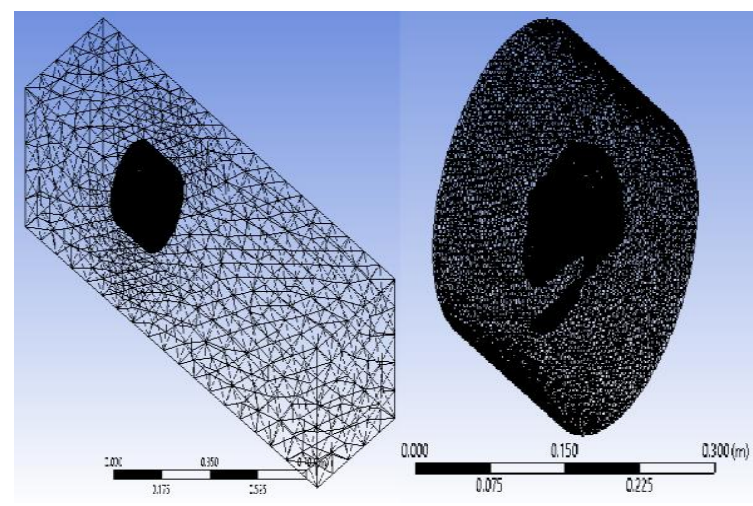

Figure 3: Meshes of the stationary and rotating domains.

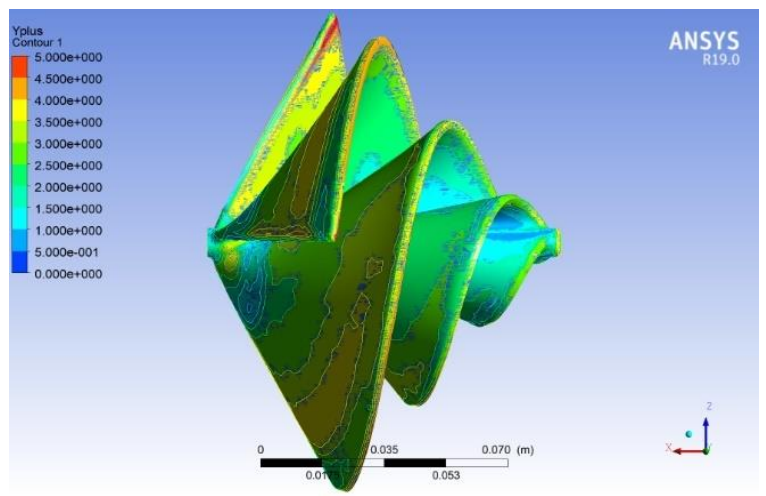

Figure 4: A contour of $\mathrm{Y}^{+}$for the turbine rotor.

To ensure mesh-independency of the computational results, careful mesh study was carried out by increasing the number of mesh elements. Five mesh tests for the five models of the turbine blades were carried out as shown in Figure 5. The tests were carried out by considering the variation of power coefficient $(\mathrm{Cp})$ of the blades with the number of mesh elements. Based on the results of Fig. 4, the number of mesh elements of all models was about $1.2 \times 10^{6}$ except the 1 -aspect ratio (back-side elongation) model was about $2 \times 10^{6}$ due to large blades area.

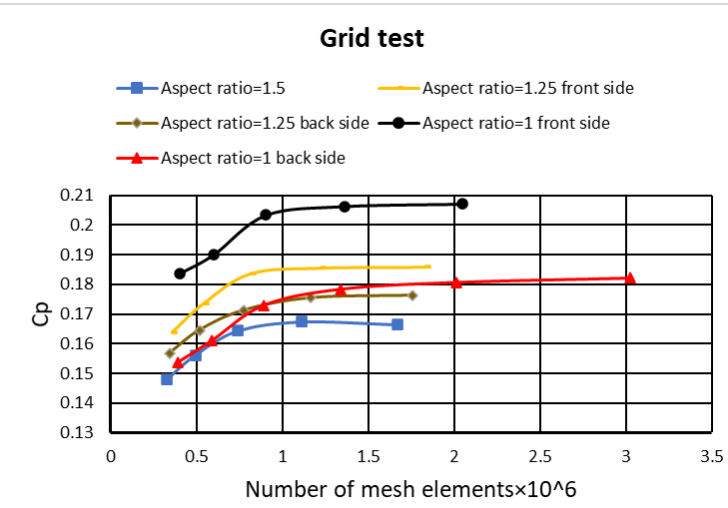

Figure 5: Grid test for the five models.

Figure 6 shows the overall computational domain, which includes the inner rotating domain of the Archimedes wind-turbine and the outer stationary domain of the flow field, which was set to $0.4 \times 0.4$ $\mathrm{m}^{2}$ [10-12]. Consequently, the blockage ratio of the frontal area which defined as the ratio of the rotor area to the front area of stationary domain was $11 \%$. A previous investigation [25] suggested that the blockage ratio, based on the frontal area, should be less than $14 \%$. Thus, the effect of the blockage ratio is negligible for the present study. The overall length of the outer stationary domain was set as $1.5 \mathrm{~m}$, which is 10 times the turbine diameter to ensure flow demonstration at the outlet section of the computational domain [10-12]. The turbine is located at 2.5 times the rotor diameter from the domain inlet.

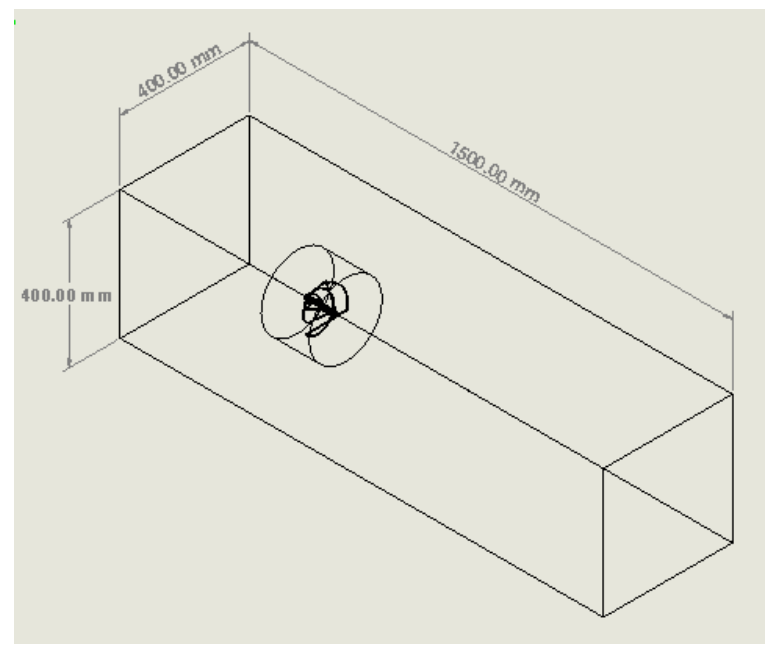

Figure 6: Dimensions of the wind turbine physical domain. 


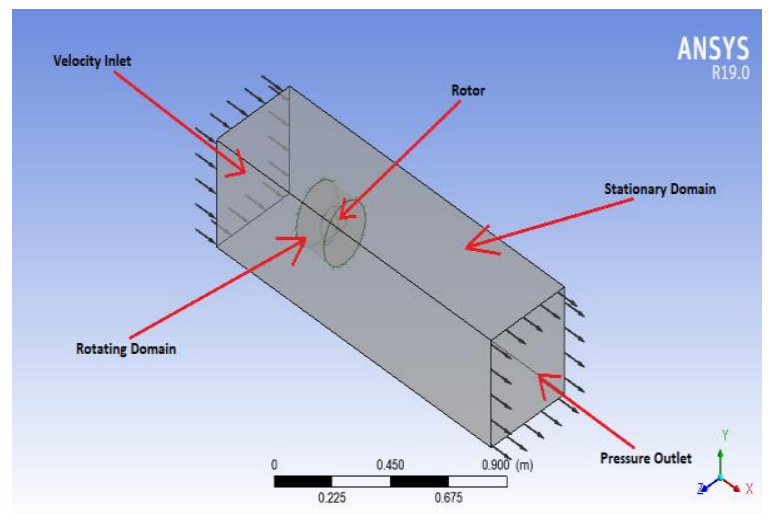

Figure 7: Inner rotating domain of the Archimedes windturbine and the outer stationary domain with boundary conditions.

As can be seen in Figure 7, the design wind speed (U) of $5 \mathrm{~m} / \mathrm{s}$ was set at the inlet boundary. At the outlet boundary, gauge pressure zero Pascal was applied for the four turbine models [9-13, 19, 21, 23]. The tip-speed ratio varied between 0.15 and 3.29, consequently. Fifteen cases for each model were solved at $U=5 \mathrm{~m} / \mathrm{s}$. Free-slip boundaries were applied to the four side surfaces of the stationary domain [10].

Solving mode was set to steady-state type $[9,19$, 22]. In order to accurately predict the flow separation, the Shear Stress Transport (SST) turbulence model was used [9-12, 21, 23, 26, 27]. The SST k- $\omega$ has the advantages of both $k-\varepsilon$ and $k-\omega$ models, where $\mathrm{k}$ is the turbulence kinetic energy, and $\varepsilon$ is the dissipation rate of kinetic energy and $\omega$ is specific rate of dissipation [28]. The frame change used is the frozen rotor mode $[9,10]$. The conservative interface flux for mass and momentum was used. The inlet and outlet air flows through the boundary surfaces were automatically calculated. The General Grid Interface (GGI) was used to the three sharing surfaces between stationary and rotating domains $[9-12,19]$. The solution convergence was established by monitoring the residual history and the convergence criterion of RMS was $10^{-5}$ for all variables.

Equations of continuity and momentum that were applied in this work are as follows:

$$
\begin{gathered}
\nabla \cdot(\rho U)=0 \\
\nabla \cdot(\rho U \otimes U)-\nabla \cdot\left(\mu_{e f f}-\nabla U\right)=-\nabla P+\nabla \cdot \\
\left(\mu_{e f f}-\nabla U\right)^{T}+B
\end{gathered}
$$

Where, $\mu_{\text {eff }}$ is the effective viscosity coefficient and $\mathrm{B}$ is the body force. The shear stress transport model is represented by the following equations:

$$
\begin{gathered}
\frac{\partial}{\partial x_{i}}\left(\rho k u_{i}\right)=\frac{\partial}{\partial x_{j}}\left(\Gamma_{k} \frac{\partial k}{\partial x_{j}}\right)+\breve{G}_{k}-Y_{k} \\
\frac{\partial}{\partial x_{i}}\left(\rho \omega u_{i}\right)=\frac{\partial}{\partial x_{j}}\left(\Gamma_{\omega} \frac{\partial \omega}{\partial x_{j}}\right)+\breve{G}_{\omega}-Y_{\omega}
\end{gathered}
$$

Where, $\breve{G}_{\mathrm{k}}$ is the generation of turbulence kinetic energy for the mean velocity gradient, and $\breve{G}_{\omega}$ is shown as the generation of accumulation rate. For $\Gamma_{k}$, $\Gamma_{\omega}, Y_{k}, Y_{\omega}$, each of them is shown as the effective diffusivity and turbulence dissipation of $\mathrm{k}$ and $\omega$. The torque coefficient and power coefficient were calculated from the following equations:

$$
\begin{gathered}
C_{t}=\frac{\text { torque }}{0.5 \times \rho \times A \times U_{\infty}{ }^{2} \times R} \\
\omega=2 \times \pi \times \frac{N}{60} \\
\text { Power }=\text { torque } \times \omega \\
C_{P}=\frac{\text { Power }}{0.5 \times \rho \times A \times U_{\infty}{ }^{3}}
\end{gathered}
$$

Where, $\rho$ is the air density, $A$ is turbine area, $U_{\square}$ is free-stream velocity, and $\omega$ is the angular velocity.

\section{Validation}

Figure 8 shows the relation between torque coefficient and tip-speed ratio (TSR) for the present studied scaled-down 1.5 aspect-ratio model in comparison to the results of Lu et al. [9]. The results of $\mathrm{Lu}$ [9] were based on both a steady-state numerical study and a theoretical study based on angular momentum equation for the full-scale model.

Generally, as shown in Figure 8, the values of the torque coefficient $(\mathrm{Ct})$ decrease with the tip-speed ratio (TSR) for both the present investigation and those of Lu et al. [9]. However, there is a noticeable divergence between the two computational results and the theoretical results at very low tip-speed ratios till TSR approaches 1.0. Both computational results are in a good agreement with the theoretical torque coefficient from $T S R=1$ to 2 . At relatively high tipspeed ratio $(\mathrm{TSR}>2)$, the present computational results of the scaled-down model are closer to the theoretical values of the torque coefficient than results of Lu et al. [9].

Thus, the good agreement of the present computational results with the theoretical model of Lu et al. [9], for most of the values of TSR, gives worthy confidence in the present computational method. 


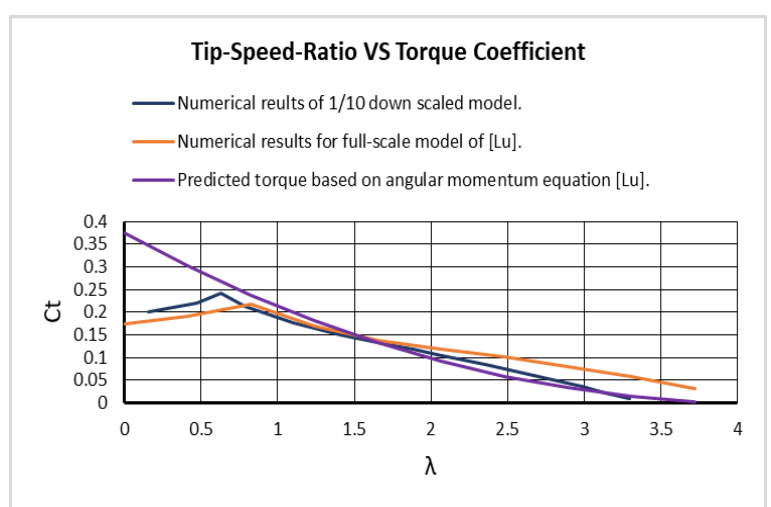

Figure 8: Numerical validation with Lu et al. [9].

At tip-speed ratio $(\mathrm{TSR}<2)$ the error percentage is less than 20\%, As shown in figure 9. However, the error percentage increases at tip-speed ratio $(\mathrm{TSR}>2)$ the percentage error increases but the results of the current investigation are closer to the theoretical results than $\mathrm{Lu}[9]$.

\section{Error Percentage Between 1/10 Down-Scaled Model and Results of Lu}

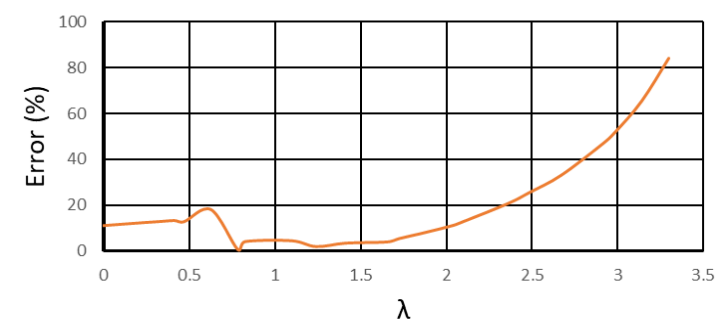

Figure 9: Error Percentage between the current results and results of $\mathrm{Lu}[9]$ with respect to tip-speed ratio.

\section{Results and Discussion}

Figure 10 shows the variation of power coefficient (Cp) with the tip-speed ratio for the five models at wind speed $5 \mathrm{~m} / \mathrm{s}$. As can be seen in Fig. 10, the front-side elongation not only increases the power coefficient, but also reaches the highest power coefficient at lower tip-speed ratio than other models, which is perfect for low wind-speed areas and as such heavy-weight turbine. The 1-aspect ratio (front-side elongation) has the highest power coefficient of 0.249 at $\mathrm{TSR}=1.413$, which is higher than the 1.5 aspect ratio model by $11.2 \%$. However, the 1 -aspect ratio (front-side elongation) model has the highest power coefficient but it has the most turbine length, which leads to turbine vibration and fluctuation, which causes less overall efficiency and reduces bearing life-time. Figure 9 shows the torque coefficient versus tip-speed ratio for the five models. The 1-aspect ratio (back-side elongation) model has the lowest power coefficient but it has the highest torque coefficient at very low tip-speed ratio. The reason of the high torque of the 1-aspect ratio (backside elongation) model is that it has the largest contact-blade area with the wind flow, which gives it the highest solidity, which is the same working concept of the old multi-blades wind turbines. Table [2] shows the highest power and torque coefficients for the five models at their corresponding tip-speed ratios.

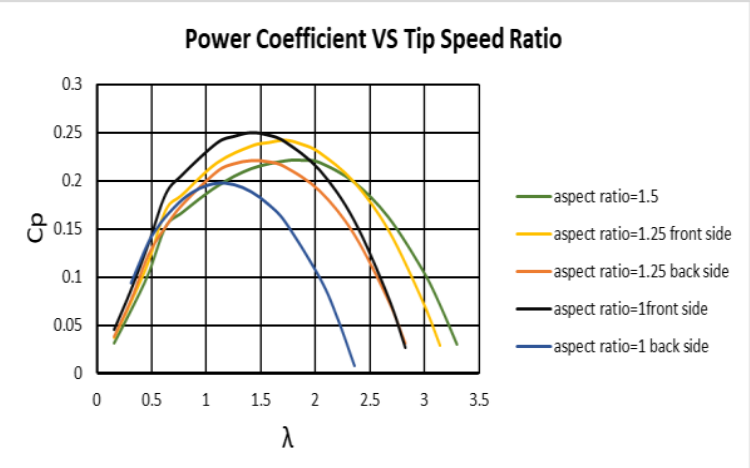

Figure 10: Power coefficient VS tip-speed ratio for the five models.

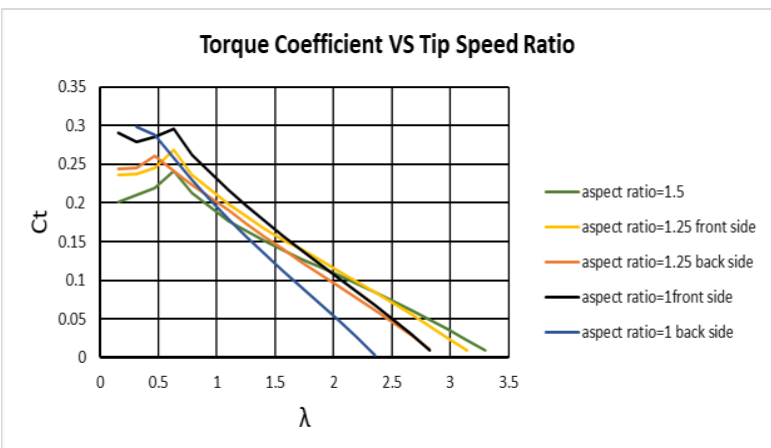

Figure 11: torque coefficient VS tip-speed ratio for the five models.

Table 2: The highest value of power and torque coefficients with respect to the tip-speed ratio of the five models.

\begin{tabular}{|c|c|c|c|c|c|}
\hline AR & $\begin{array}{c}\text { Elongation } \\
\text { Side }\end{array}$ & $\begin{array}{c}\text { Max. } \\
\mathrm{C}_{\mathrm{p}}\end{array}$ & $\begin{array}{c}\text { TSR at } \\
\max . \\
\mathrm{C}_{\mathrm{p}}\end{array}$ & $\begin{array}{c}\text { Max. } \\
\mathrm{C}_{\mathrm{t}}\end{array}$ & $\begin{array}{c}\text { TSR at } \\
\text { max. } \mathrm{C}_{\mathrm{t}}\end{array}$ \\
\hline 1.5 & - & 0.221 & 1.884 & 0.241 & 0.628 \\
\hline 1.25 & Front & 0.241 & 1.727 & 0.268 & 0.628 \\
\hline 1.25 & Back & 0.220 & 1.413 & 0.260 & 0.471 \\
\hline 1 & Front & 0.249 & 1.413 & 0.295 & 0.628 \\
\hline 1 & Back & 0.197 & 1.099 & 0.298 & 0.314 \\
\hline
\end{tabular}


Figures 12 and 13 show the power and torque coefficients with respect to tip-speed ratio, respectively for the 1.5 -aspect ratio model from 5 to $12 \mathrm{~m} / \mathrm{s}$ with an interval of $1 \mathrm{~m} / \mathrm{s}$. Figures 14 and 15 show the power and torque coefficients with respect to tip-speed ratio, respectively, for the 1-aspect ratio model (front-side elongation) from 5 to $12 \mathrm{~m} / \mathrm{s}$ with an interval of $1 \mathrm{~m} / \mathrm{s}$. As predicted, there is no noticeable difference between the results at different wind speeds for the same model.

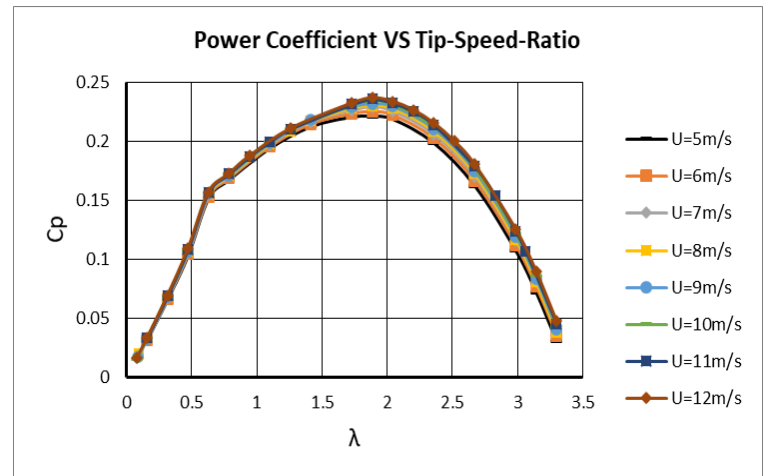

Figure 12: Power coefficient VS tip-speed ratio for 1.5aspect ratio model.

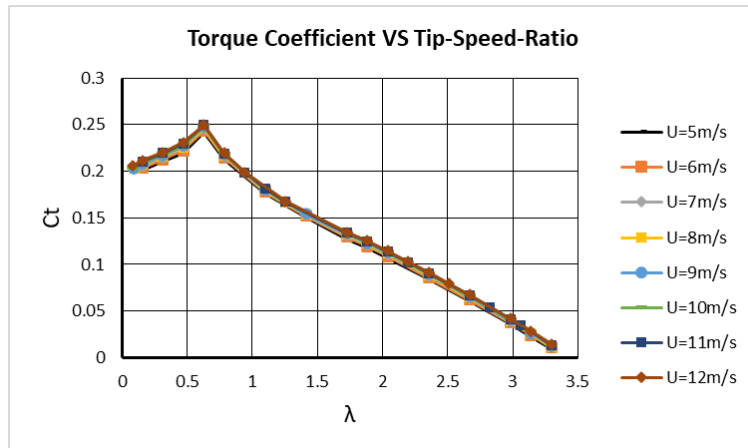

Figure 13: Torque coefficient VS tip-speed ratio for 1.5aspect ratio model.

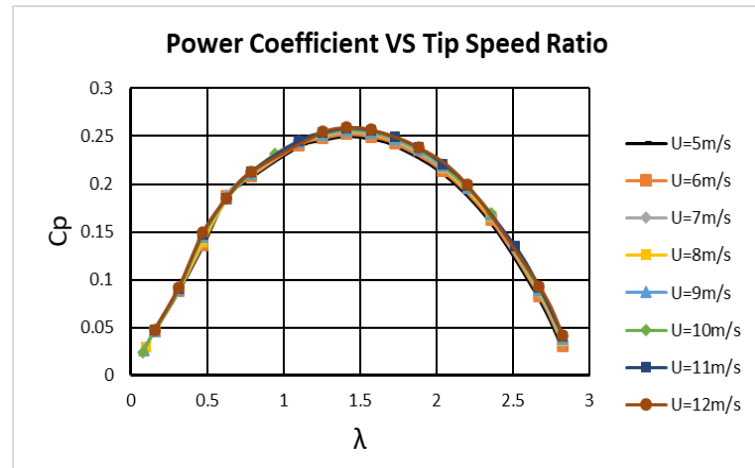

Figure 14: Power coefficient VS tip-speed ratio for 1aspect ratio model.

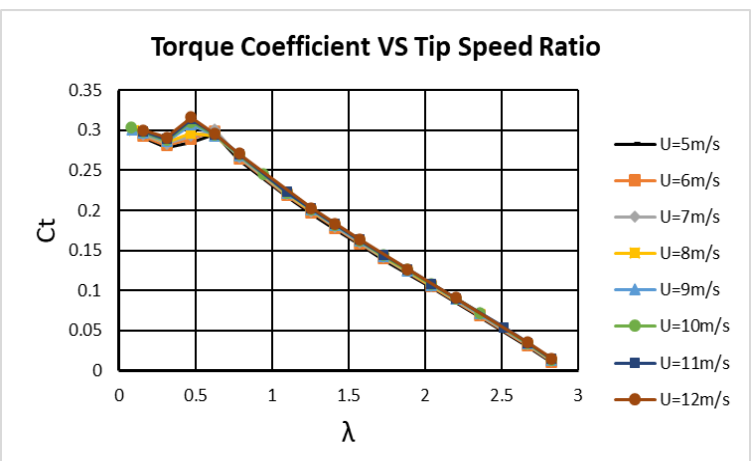

Figure 15: Torque coefficient VS tip-speed ratio for 1aspect ratio model.

\section{Conclusions}

The present computational study demonstrates the variation of the Archimedes wind-turbine performance (power and torque coefficients) with the aspect ratio. The computational investigation covered wind speeds from 5 to $12 \mathrm{~m} / \mathrm{s}$ with an interval of 1 $\mathrm{m} / \mathrm{s}$. The aspect ratios were $1.5,1.25$ (front- and back-elongation), and 1 (front- and back-elongation).

Based on the above results and discussions, the following concluding points can be stated:

- Maximum power coefficient $\left(C_{p}\right)$ is 0.249 at $T S R=1.413$, which is for the 1 -aspect ratio (frontelongation) model.

- $\quad$ Maximum torque coefficient $\left(C_{t}\right)$ is 0.298 at TSR $=0.314$, which is for the 1 -aspect ratio (backelongation) model.

- At the lowest tip-speed ratio $(T S R)$, the Archimedes wind-turbine has the unusual behaviour of increasing torque with the increase of TSR. This behaviour needs full-scale experimental investigation for better explanation.

- Front-side elongation models not only increase the power coefficient but also has optimum TSR lower than 1.5-model and back-side elongation models which make it perfect choice for low wind-speed areas, where the turbine cannot reach high TSR.

- It is not recommended to decrease the aspect ratio less than 1 because more elongation leads to more vibration and fluctuation, which decreases the overall turbine efficiency and reduces bearing life-time.

- The 1 back-side elongation model has higher torque coefficient because it has the largest blade contact area with the flow stream which leads to easily start up and high torque, which makes it perfect for high-torque application like wind pumps. 
- Archimedes wind-turbine models in general has greater power coefficient $\left(C_{p}\right)$ at the lower tipspeed ratios than Savonious turbines, which makes Archimedes wind-turbine perfect for urban environment.

\section{References}

[1] N. Energy, Small Wind Report (Summary), World Wind Energy Association, 2012. https://wwindea.org/ [Last seen August 2020]

[2] S. A. Jaber, A. Amin, C. Clini, R. Dixon, M. Eckhart, M. ElAshry, S. Fakir, D. Gupta, and A. Haddouche, Renewables 2011 global status report. Paris, France: Renewable Energy Policy Netwrok for the 21st Century, 2011.

[3] N. Ahmed, A novel small-scale efficient wind turbine for power generation. Renewable Energy, 2013. 57: p. 79-85.

[4] Z. Simic, J. G. Havelka, and M. B. Vrhovcak, Small wind turbines-A unique segment of the wind power market. Renewable Energy, 2013. 50: p. 1027-1036.

[5] M. Bortolini, M. Gamberi, A. Graziani, R. Manzini, and F. Pilati, Performance and viability analysis of small wind turbines in the European Union. Renewable Energy, 2014. 62: p. 629-639.

[6] M. Arifujjaman, M. T. Iqbal, and J. E. Quaicoe, Energy capture by a small wind-energy conversion system. Applied Energy, 2008. 85(1): p. 41-51.

[7] R. Howell, N. Qin, J. Edwards, and N. Durrani, Wind tunnel and numerical study of a small vertical axis wind turbine. Renewable energy, 2010. 35(2): p. 412-422.

[8] H. Ji, K. C. Kim, J. H. Baek, and R. Ruijtenbeek, The aerodynamic method of the Archimedes Windturbine. 2014, South Korea.

[9] Q. Lu, Q. Li, Y.-K. Kim, and K.-C. Kim, A study on design and aerodynamic characteristics of a spiral-type wind turbine blade. Journal of the Korean society of visualization, 2012. 10(1): p. 27-33.

[10] K. C. Kim, H. S. Ji, Y. K. Kim, Q. Lu, J. H. Baek, and R. Mieremet, Experimental and numerical study of the aerodynamic characteristics of an archimedes spiral wind turbine blade. Energies, 2014. 7(12): p. 7893-7914.

[11] K. C. Kim, Y. K. Kim, H. S. Ji, J. H. Beak, and R. Mieremet, Aerodynamic Characteristics of Horizontal Axis Wind Turbine with Archimedes Spiral Blade, in ASME 2013 International Mechanical Engineering Congress and Exposition. November 15-21, 2013. San Diego, California, USA: American Society of Mechanical Engineers Digital Collection.

[12] Y. K. Kim, Q. Lu, H. S. Ji, J. H. Beak, R. Mieremet, and K. C. Kim, A multi-prong study on aerodynamic characteristics of Archimedes spiral-type wind turbine blade. energies, 2014.

[13] A. Safdari, and K. C. Kim, Aerodynamic and structural evaluation of horizontal Archimedes spiral wind turbine. Journal of Clean Energy Technologies, 2015. 3(1): p. 34-38.

[14] Q. Li, H. D. Kim, H. S. Ji, and K. C. Kim, Flow Characteristics Around Archimedes Wind Turbine according to the Change of Angle of Attack. Journal of the Korean Society of Visualization, 2013. 11(1): p. 28-33.

[15] H. S. Ji, L. Qiang, J. H. Beak, R. Mieremet, and K. C. Kim, Effect of the wind direction on the near wake structures of an Archimedes spiral wind turbine blade. Journal of Visualization, 2016. 19(4): p. 653-665.

[16] S.-M. Yang, H.-S. Ji, D.-S. Shim, J.-H. Baek, and S.-H. Park, Conical roll-twist-bending process for fabrication of metallic archimedes spiral blade used in small wind power generator.
International Journal of Precision Engineering and Manufacturing-Green Technology, 2017. 4(4): p. 431-439.

[17] H. Ji, J. Baek, R. Mieremet, and K. C. Kim, Aerodynamic characteristics of an archimedes spiral wind turbine blade according to the angle of attack change.

[18] H. S. Ji, J. H. Baek, R. Mieremet, and K. C. Kim, The aerodynamic performance study on small wind turbine with $500 \mathrm{~W}$ class through wind tunnel experiments. International Journal of Renewable Energy Sources, 2016. 1: p. 7-12.

[19] S. Chaudhary, S. Jaiswal, R. Nanda, S. Patel, and P. Kumar, Comparison of torque characteristics of Archimedes wind turbine evaluated by analytical and experimental study. International Journal of Mechanical and Production Engineering, 2016. 4(8): p. 75-78.

[20] D. S. Sandeep, K. V. Krunal, R. Karishma, C. Ravikumar, and P. Y. Deepak Raj, Design, fabrication and aerodynamic analysis of a modified Archimedes wind turbine. International Journal of Research and Scientific Innovation (IJRSI), 2017. IV(VS): p. 55-59.

[21] S. S. Rao, K. Shanmukesh, M. Naidu, and P. Kalla, Design and analysis of Archimedes aero-foil wind turbine blade for light and moderate wind speeds. International Journal on Recent Technologies in Mechanical and Electrical Engineering, 2018. 5(8): p. 01-05-01-05.

[22] S. Ebrahimi, and M. A. Ghassemi, Numerical aerodynamics analysis of the of the Archimedes screw wind turbine. Int. J Multidisciplinary Sci \& Eng, 2018. p. 12-15.

[23] H. Jang, D. Kim, Y. Hwang, I. Paek, S. Kim, and J. Baek, Analysis of Archimedes spiral wind turbine performance by simulation and field test. Energies, 2019. 12(24): p. 4624.

[24] J. H. Baek, B. S. Kim, S. k. Min, and M. Mieremet, Spiral blade unit and wind generator, W.I.P. Organization, 2017.

[25] G. Van Bussel, S. Mertens, H. Polinder, and H. Sidler. TURBY@: concept and realisation of a small VAWT for the built environment. in Proceedings of the EAWE/EWEA Special Topic conference" The Science of making Torque from Wind", Delft, The Netherlands. 2004.

[26] H. Cao, Aerodynamics analysis of small horizontal axis wind turbine blades by using 2D and 3D CFD modelling. 2011. MSc (by Research): p. 82.

[27] H. Jang, I. Paek, S. Kim, and D. Jeong, Performance prediction and validation of a small-capacity twisted Savonius wind turbine. Energies, 2019. 12(9): p. 1721.

[28] F. R. Menter, Turbulence modeling for engineering flows. Ansys, Inc, 2011. 